\title{
Study on Pile Foundation Quality Control Measures of Quanzhou Sihai Building
}

\author{
Yujie Wang \\ College of Civil Engineering, University of Science and Technology Liaoning, \\ Anshan,Liaoning,China \\ aswangyujie@126.com
}

\begin{abstract}
Keywords: pile foundation; quality; management; Control measures
Abstract. In China's engineering construction, the pile foundation has become an important foundation form of a lot of high-rise buildings and large-scale buildings. The pile foundation is the groundwork of the whole building. The pile foundation quality is very important for the whole building. Combined with the Sihai building pile foundation, the quality management and control measures are carried out on the basis of the analysis of the status quo of the project. In the construction process, the construction technology and methods of rotary bored piles are control strictly. The pouring of concrete should be continuous to ensure the depth of the steel conduit. In the rainy season construction, waterproof and drainage measures are fully prepared. The countermeasures and management measures to strengthen the quality control of pile foundation engineering are put forward from these aspects. High efficiency, high quality, low cost of project management objectives are achieved through these measures. A new level of domestic project quality management is created. The expected effect of the project quality management and control is achieved.
\end{abstract}

\section{Introduction}

At present, China's construction industry is developing very rapidly, and construction plays an increasingly important role in the national economy. The pile foundation is the most important part and the main foundation form in the construction project. The quality of the pile foundation engineering is one of most critical factors for the project's success. The pile foundation can't be seen on the outside. Its technical and quality management is particularly important. Therefore overall and comprehensive quality management work should be conducted [1]. As an important part and foundation form of the building, the pile foundation is influenced by the geological conditions and the construction is concealed. Frequently prone questions include pile concrete segregation, high-inclination, insufficient bearing capacity and the problem of broken pile. If the accident quality or quality hazards happen, the consequences may be catastrophic. The primary task of project management is to strengthen the quality control and management, to ensure safety of national property and people's lives [2]. For the quality management of the project, the lack of centralized management and effective control will result in the inaccuracy of communication and information, result in increase of time and cost, and then the quality of the project is out of control [3]. Therefore, how to ensure the quality of the project has become the primary problem. The quality control and management of pile foundation construction process is particularly important.

\section{engineering situation}

Quanzhou Sihai Building is located in Quanzhou City, Fujian Province. The project is located at the seaside. The total land area of the office building is about $11990.98 \mathrm{~m}^{2}$. The total design construction area of the project is about $115980.43 \mathrm{~m}^{2}$. The aboveground area of the building is about $88732.55 \mathrm{~m}^{2}$, and underground building area is about $27247.88 \mathrm{~m}^{2}$. The total height of building is $140 \mathrm{~m}$. There are 30 floors on the ground, 3 floors under the ground. The land shape is fan-shaped, and the terrain is flat. The plot ratio is 7.20 , the building density is $25.64 \%$, and the green land rate is $25.20 \%$. The original 
landform of the site is bay tidal flat, and it is made of artificial land. The terrain is low, and the local area is likely to cause the surface water influx in rainy season. The groundwater is affected by the environmental type and has moderate corrosion to the concrete structure. The foundation design grade is A. The basement and main pile foundation construction adopt rotary bored piles hole-making technology. The total pile number is 495 , the pile diameters are $800 \mathrm{~mm}$ and $1200 \mathrm{~mm}$ respectively, and the designed cavity length is $12.8 \sim 14.4 \mathrm{~m}$, effective pile length of $30 \sim 45 \mathrm{~m}$, the total amount of about $15500 \mathrm{~m}^{3}$. The pile foundation construction includes foundation pit support and engineering pile (including test pile). The geological formations are plain fill, silt, sand soil, weathered granite (strong weathered granite containing boulder) mainly. The area of the project belongs to the humid area. The residual sandy clay and the mud are saturated weak aquifer. According to the Geotechnical Investigation Standard, the environmental type can be classified as Class II according to the integrated site. The type of groundwater can be classified as Class B.

\section{Pile foundation characteristics}

Pile and pile platform form the pile foundation, and it is a common deep foundation to bear static load and dynamic load. The pile is located in the soil, has certain stiffness and bending resistance. It can be vertical or inclined. The pile foundation is mainly cylindrical, that is, the cross-sectional size is much smaller than the length. It is connected with the top of the pile, and forms the deep foundation together with the upper platform. The load of the superstructure is transferred to the soil through the pile foundation, and the deep part of the soil has strong bearing capacity. If the bearing capacity is insufficient, the soft soil layer can be compacted to improve the density and carrying capacity of the foundation soil. The pile foundation is in the deep soil with adequate resisting compression and pull-out capacity, so that high-rise buildings do not overturn, always in a stable state, and does not produce too much tilt and settlement [4]. The bearing capacity of pile foundation is high, the structure is stable, the settlement is small, uniform. The seismic resistance is good. It can be mechanically constructed. The pile foundation is suitable for many soils and regions and is widely used in various projects [5]. The pile foundation is suitable for the following situation: buildings in water; buildings in locations with deeper bearing stratum and higher groundwater levels; buildings that are very sensitive to settlement; seismic foundation for high-rise buildings or other important buildings. The pile foundation applies to various buildings in the earthquake area [6].

In the construction of pile foundation of Quanzhou Sihai building, the construction method of rotary drilling pile is adopted. Its advantages include: (1) The vibration is small and the noise is low. (2) It is suitable for the holes in the cohesive soil. (3) Drilling rig installation is relatively easy, and pile center can be easily achieved. (4) Drilling rig is easy to move at the construction site. (5) Drilling is faster. (6) Project cost is relatively low. (7) The center of the pile is close to the site boundary. (8) Environmental pollution is relatively light. (9) High-quality pile foundation can be obtained.

\section{Control measures of construction process}

In the construction of the pile, the first thing is to level the site and clear the obstacles. The next is to determine drilling machine positioning, bury protective pile. Drilling machine positioning device will ensure that the center deviation is less than $1.0 \mathrm{~cm}$. One of the most important things is to maintain vertical of the first and second sets of casings. It is the key to ensuring quality. Verticality is checked with measuring instruments. After the bottom of the casing was pressed into a certain depth (about $1.5 \mathrm{~m})$, the casing and pile center deviation is checked with a protective pile to ensure that the deviation is less than $1.0 \mathrm{~cm}$. Percussion clamshell is used to grab the soil, the casing swings at the same time. The casing is vertically pressed into the soil. And then the latter casing is connected, the previous step is repeated until the depth of drilling meeting the design requirements, and accurate records of drilling raw data is obtained. 
During construction an important thing is that steel cage raw materials used should be strictly double-controlled and can be used qualified. Welders with certificate can work. Before steel cage is produced, the steel cage production platform should be laid and the steel cage production positioner should be installed. The PE pipe should be set to ensure accurate positioning. In the production of steel cage, the construction process quality of piling up and lifting is strictly controlled to ensure them compliance with the engineering code requirements, to avoid the occurrence of insufficient bearing capacity and poor quality of the pile.

The mixing ratio of concrete should be adapted to the construction of underwater concrete with conduit method. Specification and type of conduit, lifting transporter, mixer and other equipment are selected reasonably according to the pile diameter, pile length and the required amount of perfusion. Conduit position in the pile hole should always be in the middle to prevent the conduit and steel cage hitting together. Construction sequence is as follow: placement of the steel cage $\rightarrow$ installation of the pipe $\rightarrow$ the inside of the pipe closing to the slide valve $\rightarrow$ pouring the first batch concrete $\rightarrow$ pouring the concrete continuously until the pile top $\rightarrow$ pulling out the steel casing. Concrete must be continuously poured. Otherwise following pouring concrete can't flow out from the conduit which will lead to broken pile after initial setting of the first pouring concrete.

The process of concrete infusion is executed strictly accordance with the construction process and standard implementation to avoid the emergence of concrete segregation, insufficient bearing capacity, broken pile and other quality problems.

\section{Control Measures of Quality Management in Rainy Season}

The climate of Quanzhou area belongs to maritime climate. Sudden rainfall is likely to occur. It's rainy season during the construction peak period. Whether the waterproof and drainage measures are reasonable has great impact on the pile foundation construction. Serious rainstorm will cause a lot of property damage, even casualties, and the quality of the project is difficult to guarantee. So the waterproof and drainage measures and the rainy season construction measures must be done well to ensure the quality of pile foundation and the whole building construction.

(1)Preparation measures in rainy season

The project manager is responsible for organizing the leading group of the rainy season construction and develops flood control and various measures according to the actual situation. The workers on the site are organized, trained, and informed the precautions. All staff should be aware of the overall layout of the site, enhance the quality and safety awareness and avoid accidents.

Preparations for rainy season construction should be done. The rainy season construction scheme is compiled. In the rainy season construction preventive measures including waterproof measures and drainage measures are taken to avoid the negative influence of this rainy seasonal factor. Full-time staffs at night shift should ensure that there are always staffs on duty at the construction site. Full-time staffs on duty listen to weather forecasts and publish it to prevent sudden heavy rain. Materials and equipment management departments prepare the pump, straw, pumping hose, tarpaulin and other rainy season materials required in advance. In the event of an accident, the staffs approach in time, detect and maintain water pumps and other important drainage equipment in advance.

(2)Waterproof and drainage measures in rainy season

Drainage facilities should be strictly checked. The area includes the construction site and living areas. The drainage ditches are dig near the construction and living area. The rainwater flow into the sewage pipes through drainage ditches to ensure that the surrounding rain does not flow into the foundation pit. The drainage channels are set where needed. The rainwater discharge ports are checked strictly. The rainwater should be discharged to the outside of the site and there are not hydrops in the site and foundation pit. Before the arrival of the rainy season, the power-related facilities are safe and isolate of rainwater. Problematic facilities are repaired in time to ensure electricity safety. 
There are some points for attention. The site of steel piling must be high to prevent steel suffering corrosion of water. The anti-rust treatment should be accomplished according to the actual situation if the steel are rained. If the steel corrosion is serious, they can't be used and must be waste. The steel of late poured band is strictly prohibited corrosion. The late poured band is closed with waterproof layer board and covered with plastic sheeting.

The rainy season construction scheme and drainage measures can reduce the negative influence on the quality of the pile, improve the bearing capacity and ensure the quality of the engineering.

\section{Conclusions}

During the whole construction process, the comprehensive quality management methods are used, and specific control measures and guarantee system are put forward. The quality control technology, control measures and countermeasures are put forward from the construction technology process of rotary bored piles and measures of rainy season construction. The quality assurance system of pile foundation project is established, and the engineering task is completed better.

The initial expected quality target is that $90 \%$ of the piles reach classI standards to meet the Luban Award reporting conditions. During the implementation process of Quanzhou Sihai Building, the overall goal has been ultimately completed by strengthening the project quality management and control. The project has met the current construction quality acceptance standards, local, industry, national standards, and Luban Award reporting conditions. More than 90\% of the piles have reached classI of pile construction standards. Under adverse environmental conditions, by strengthening the management and control of rotary bored piles technology process and rainy season construction measures, the verticality of the pile is ensured effectively, the broken pile and the insufficient bearing capacity are avoided. The concrete pile and the internal concrete core are complete, continuous after the construction. Coarse and fine aggregate are evenly distributed, and no segregation occurs. The construction task is completed with high quality. The quality objectives of the project department are fully realized. The management and control measures of the project bring valuable experiences for the future similar project, and bring useful inspiration for the project constructions of other construction units.

\section{References}

[1] Jingyang Wang, Study on Construction Technology of Pile Foundation in High-rise Buildings[J]. New Products of China, In Chinese, 2012, 16, p196-197

[2] Xin Xu, Study on Selection of Building Foundation Type in Loess Area [D]. Chang'an University, 2008

[3] Peter E.D.Love, Influence of Project Type and Procurement Method on Rework Costs in Building Construction Project[J]. Journal of Construction Engineering \& Management, 2014, 128(1):18-29

[4] Zhongfu Xiang, Introduction of Civil Engineering [M]. Chongqing University Press, 2012

[5] Sheqin Peng, Foundation Engineering [M]. China Construction Industry Press, In Chinese, 2012

[6] Liangjin Ling, Study on Foundation Treatment and Pile Foundation Selection [D]. Xiamen University, 2009 